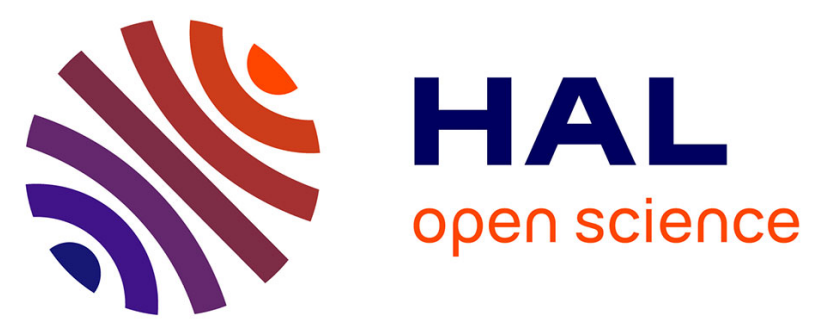

\title{
CRYSTALLINE SELF-AGGREGATION AND A PRESSURE DRIVEN SOLID-SOLID PHASE TRANSITION IN A FLUORINATED LANGMUIR MONOLAYER
}

D. Jacquemain, S. Grayer Wolf, F. Leveiller, M. Lahav, L. Leiserowitz, M.

Deutsch, K. Kjaer, J. Als-Nielsen

\section{To cite this version:}

D. Jacquemain, S. Grayer Wolf, F. Leveiller, M. Lahav, L. Leiserowitz, et al.. CRYSTALLINE SELFAGGREGATION AND A PRESSURE DRIVEN SOLID-SOLID PHASE TRANSITION IN A FLUORINATED LANGMUIR MONOLAYER. Journal de Physique Colloques, 1989, 50 (C7), pp.C7-29C7-37. 10.1051/jphyscol:1989704 . jpa-00229677

\section{HAL Id: jpa-00229677 https://hal.science/jpa-00229677}

Submitted on 1 Jan 1989

HAL is a multi-disciplinary open access archive for the deposit and dissemination of scientific research documents, whether they are published or not. The documents may come from teaching and research institutions in France or abroad, or from public or private research centers.
L'archive ouverte pluridisciplinaire HAL, est destinée au dépôt et à la diffusion de documents scientifiques de niveau recherche, publiés ou non, émanant des établissements d'enseignement et de recherche français ou étrangers, des laboratoires publics ou privés. 


\title{
CRYSTALLINE SELF-AGGREGATION AND A PRESSURE DRIVEN SOLID-SOLID PHASE TRANSITION IN A FLUORINATED LANGMUIR MONOLAYER
}

\author{
D. JACQUEMAIN, S. GRAYER WOLF, F. LEVEILLER, M. LAHAV, L. LEISEROWITZ, \\ M. DEUTSCH *, K. KJAER** and J. ALS-NIELSEN ${ }^{*}$ * \\ Structural Chemistry Department, Weizmann Institute of Sciences, \\ IL-Rehovot 76100, Israel \\ * Physics Department, Bar-Ilan University, IL-Ramat-Gan 52100, Israel \\ ** Physics Department, Ris $\phi$ National Laboratory, DK-4000 Roskilde, \\ Denmark
}

\begin{abstract}
Résumé - Nous présentons une étude de monocouches monomoléculaires du surfactant fluoré PFA, utilisant les techniques de diffraction d'incidence razante (GID) et de réflexion de rayons $\mathrm{X}(\mathrm{XR})$ issus d'une source synchrotron. Les films non comprimés forment spontanément des domaines cristallins émettant un signal GID intense. Lorsqu'ils sont comprimés et décomprimés, ces films changent de structure cristalline. Pour de fortes pressions de surface, les molécules s'arrangent dans un réseau hexagonal et sont alignées verticalement. Lorsque la pression est relachée, les molécules s'inclinent en restant rigides, déformant l'arrangement original. La mesure de séries de colonnes de Bragg indique un angle d'inclinaison d'environ $20^{\circ}$ pour une pression de surface de 10 $\mathrm{mN} / \mathrm{m}$ et de $25^{\circ}$ pour les films non comprimés; l'inclinaison des molécules se faisant vers leur plus proche voisine.
\end{abstract}

\begin{abstract}
Monolayers of PFA, a fluorinated surfactant, on water were studied using synchrotron X-ray grazing incidence diffraction (GID) and reflectivity measurements (XR). The uncompressed monolayer is found to self-assemble into crystalline domains giving a strong GID peak. Upon compression and decompression a surface pressure driven solid-solid phase transition takes place. A hexagonal lattice with vertical molecules at high pressure undergoes a distortion due to a rigid molecular tilt as the pressure is decreased. Bragg rod scans provide conclusive evidence for a tilt of about $20^{\circ}$ at $10 \mathrm{mN} / \mathrm{m}$ and show the tilt to be towards nearest neighbours. The uncompressed monolayer has a molecular tilt of about $25^{\circ}$.
\end{abstract}

\section{1 - INTRODUCTION} subphases

Langmuir monolayers induce epitaxial growth of three-dimensional crystals from supersaturated

Our interest in the molecular interactions between Langmuir monolayers and crystals grown epitaxially to them from the subphase has led us to study the two-dimensional (2D) crystal structures of these amphiphilic monolayers at the molecular level. This was achieved by exploiting the recently developed techniques of grazing-incidence synchrotron $X$-ray diffraction (GID) [1] including Bragg rod (BR) measurements [2,3], and specular reflectivity (XR) [4] from air-liquid interfaces.

It has been shown that $\alpha$-glycine crystals grow epitaxially to $\alpha$-amino acid Langmuir monolayers, with stereospecifically attached faces [5a,b]. For instance, as shown in Fig. 1, a Langmuir monolayer of Palmitoyl-R-lysine (PL) (see formula below) induces $100 \%$ oriented nucleation of $\alpha$-glycine by the (010) face. $R$ (rectus, right) denotes the chirality of the molecule about the asymmetric carbon atom marked $\stackrel{C}{\mathrm{C}}$ below. $\mathrm{S}$ (sinister, left) denotes the mirror image.

$$
\text { (R) } \mathrm{CH}_{3}-\left(\mathrm{CH}_{2}\right)_{14}-\mathrm{CO}-\mathrm{NH}-\left(\mathrm{CH}_{2}\right)_{4}-\stackrel{*}{\mathrm{C}} \mathrm{H}\left(\mathrm{NH}_{3}{ }^{+}\right) \mathrm{CO}_{2}^{-}
$$

Crystalline $\alpha$-glycine (Space group P2 $1 / \mathrm{n}$, cell constants $a=5.10 \AA, b=12.0 \AA, e=5.46$ $\AA$ and $\beta=111^{\circ}$ ) has a packing arrangement [6] consisting of hydrogen-bonded centrosymmetric bilayers in the ac plane. Its molecular cross-sectional area in the ac plane is $25.9 \AA^{2}$. The oriented binding of $\alpha$-glycine crystals under the resolved PL monolayer was 
explained by the formation of an analogous bilayer between the PL monolayer head-groups and an underlying layer of glycine molecules via a pseudo centre-of-symmetry as depicted in Figure 1B. This proposal was confirmed by the structure determination of PL monolayers using GID and XR measurements [1a,7]. Compressed PL monolayers form 2D crystalline powders and revealed two diffraction peaks corresponding to the $(1,0)+(1, \overline{1})$ and $(1, \overline{2})$ reflections. The monolayer unit cell constants derived from these reflections are $a=5.03 \AA ; c=5.46 \AA$ and $\beta$ $=117.8^{\circ}$, corresponding to a molecular area of $24.3 \AA^{2}$. These results combined with the XR profiles showed unambiguously that an excellent structural match was found between the packing arrangement of the glycyl head-groups of $\mathrm{PL}$ and the glycine layers in the growing crystal.

Fluorocarbon monolayers of $1 \mathrm{H}, 1 \mathrm{H}, 2 \mathrm{H}, 2 \mathrm{H}$-perfluorododecyl-S-aspartate (PFA, see formula below) induce less perfect epitaxial nucleation of $\alpha$-glycine, in that crystals were found attached to PFA by both the $(010)$ and (010) faces in a ratio of about $65 / 35$ in average [5]. The crystalline structure of compressed PFA monolayers determined by GID and XR [8] has an hexagonal unit cell $\left(a=b=5.74 \AA ; \gamma=120^{\circ}\right.$, molecular cross-sectional area $\left.28.5 \AA^{2}\right)$. Although the epitaxial match with $\alpha$-glycine layers in a 3D crystal is less ideal than with PL, reasonable hydrogen bonding can still be formed between a glycine layer and the monolayer head-groups. This may account for the observed crystallization results.

(s) $\mathrm{CF}_{3}-\left(\mathrm{CF}_{2}\right)_{9}-\left(\mathrm{CH}_{2}\right)_{2}-\mathrm{OCO}-\mathrm{CH}_{2}-\stackrel{*}{\mathrm{C}} \mathrm{H}\left(\mathrm{NH}_{3}{ }^{+}\right) \mathrm{CO}_{2}^{-}$

Sodium chloride as well has been shown to nucleate from Langmuir $\alpha$-amino acid monolayers, but from different crystal faces, depending on $\mathrm{pH}$ and other conditions [5c]. In this case the epitaxial match is insured by electrostatic interactions between the charged head-groups of the monolayer and ions in the $\mathrm{NaCl}$ crystal nucleating face. Remarkably, when the monolayers were expanded up to five times their limiting molecular area, glycine and sodium chloride crystals grew in the same oriented fashion from the interface [5b]. We therefore proposed that the oriented growth of these crystals at very expanded states of the surfactant provided evidence that the monolayers self-aggregate into crystalline clusters even in the so-called "liquid-expanded" or "gas" phases [9]. However, it was not possible to detect these clusters for expanded PL monolayers by GID; the two diffraction peaks observed for the compressed monolayer disappeared upon reduction of surface pressure below $10 \mathrm{mN} / \mathrm{m}$ [1a,7]. In this context, the crystalline structure as a function of surface pressure of PFA monolayers was extensively studied via GID and XR techniques [3,8]. The results, combined with the study of Bragg rod profiles will be described and analyzed in detail here. PFA monolayers display two interesting features: a solid-solid phase transition at intermediate surface pressures (about 20 $\mathrm{mN} / \mathrm{m}$ ) and more strikingly, crystalline self-clustering in their expanded state.

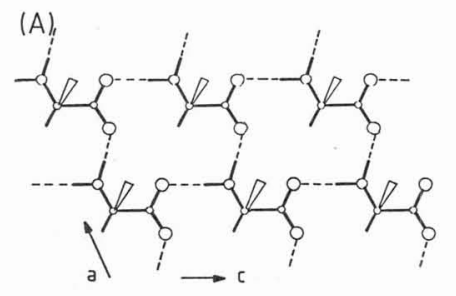

(B)

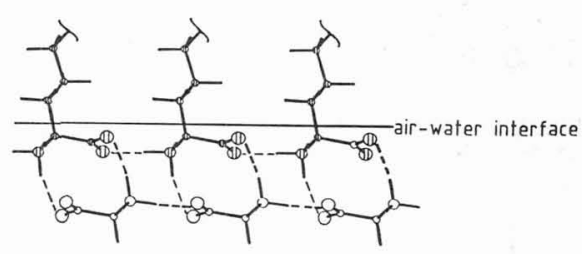

Fig. 1. A. The deduced packing arrangement of the surfactant PL in a view projected onto the monolayer plane. Hydrogen-bonding within the layer is represented by dashes. The wedge represents the projected side chain. $B$. Side view of the surfactant-glycine bilayer. The molecules with darkened atoms represent the surfactant monolayer. The molecules with light atoms represent the monolayer of $\alpha$-glycine.

\section{2 - EXPERIMENTAL}

The measurements were carried out using the liquid surface diffractometer on line D4 at Hasylab, DESY, Hamburg. A sealed and thermostated Langmuir trough equipped with a Wilhelmy balance is mounted on the diffractometer. For the Bragg rod (BR) and GID measurements detection was by a vertical linear position sensitive detector (PSD) mounted behind a horizontally collimating Soller collimator (Fig. 2). For XR measurements a scintillation detector and a horizontal slit were employed. All measurements were done over a subphase of Millipore water $(\mathrm{pH}=5.8)$ at $20^{\circ} \mathrm{C}$ and a wavelength $\lambda=1.38 \AA$. Further details are given in $[1 \mathrm{a}, 7,8]$. 
Fig. 2. Top view and side view of the GID setup and geometry. The footprint of the grazing incidence beam is indicated by the darker area of the Langmuir film. The PSD has its axis along the vertical direction $z$. Only the crossed-beamarea $A B C D$ lying in the $x y$ plane contributes to the scattering.

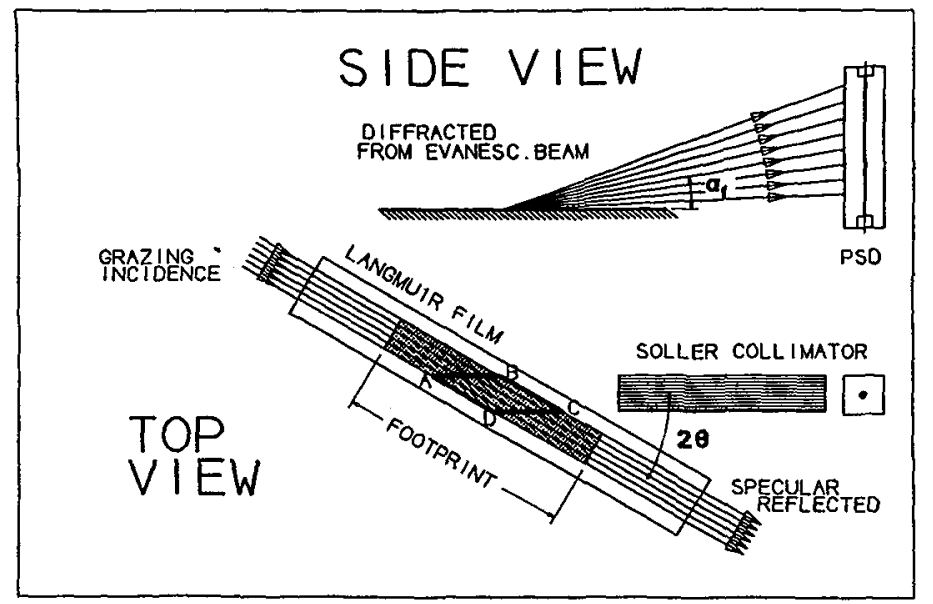

\section{3 - RESULTS}

Grazing incidence $X$-ray diffraction measurements at different surface pressures

The $\pi$-A diagram of S-PFA (Fig. 3) shows a change in slope at surface pressure of 20 to $30 \mathrm{mN} / \mathrm{m}$, and a phase transition is clearly indicated by the GID data as well.

Fig. 3. Pressure $(\pi)$ versus area (A) isotherm of S-PFA. The measurements were performed at $20^{\circ} \mathrm{C}$ using a Wilhelmy balance. PFA limiting area per molecule is $28.5 \AA^{2}$. The arrows indicate points where the Xray measurements were carried out.

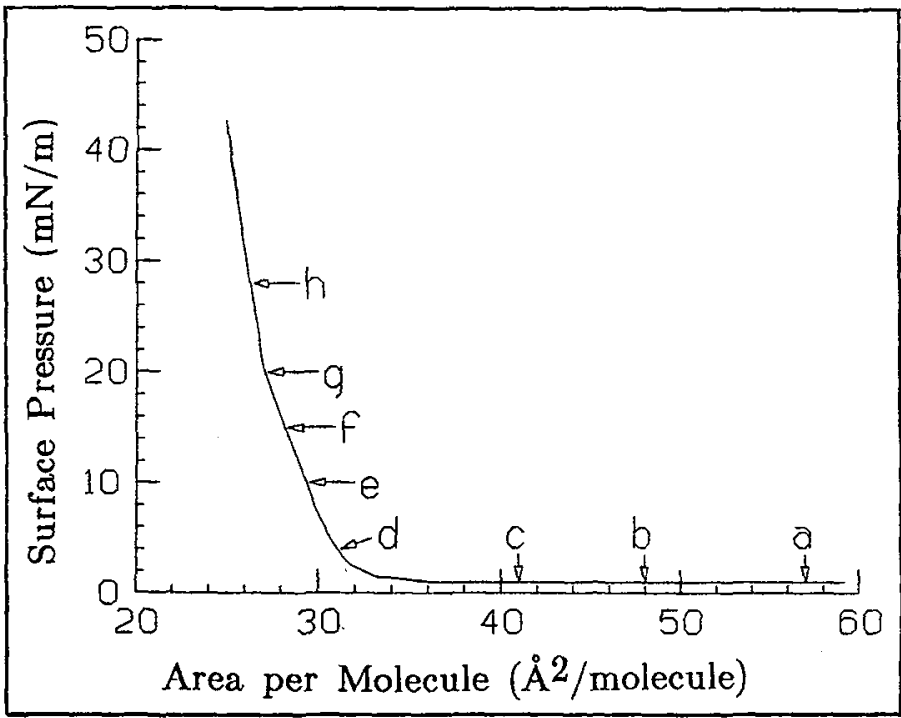

The diffraction measurements were performed at an angle of incidence $\alpha=0.85 \cdot \alpha_{c}$, where $\alpha_{c}=0.138^{\circ}$ is the critical angle for total external reflection, upon compression (Fig. 4) and decompression [8]. For a 2D periodic structure of a monolayer lying in the $x y$ plane, Bragg diffraction occurs when the component of the scattering vector in the plane of the monolayer $q_{x y}$ coincides with a reciprocal lattice vector. No condition is imposed on the vertical component $\mathrm{q}_{\mathrm{z}}$ of the scattering vector. Thus, as opposed to $3 \mathrm{D}$ crystals where Bragg diffraction leads to spots corresponding to $h k l$ reciprocal lattice points, a $2 \mathrm{D}$ crystal scatters in Bragg rods parallel to the $\mathrm{q}_{\mathrm{z}}$-axis passing through each reciprocal point $h k$ in the monolayer plane. The intensity distribution along these rods is modulated by the molecular structure factor. The finite length of the PSD corresponds to a measuring window $\Delta q_{z}=0.33 \AA^{-1}$. Thus, in GID experiments only part of the Bragg rod contributes to the signal and consecutive scans centered on higher $q_{z}$ had to be performed (Fig. 4B). 
A
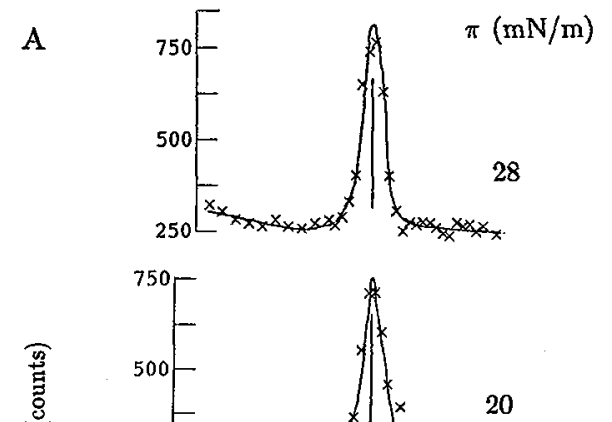

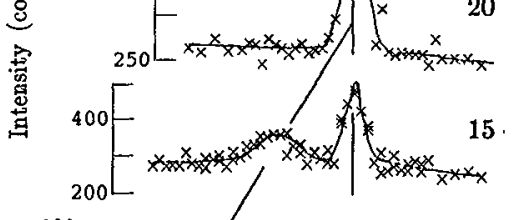

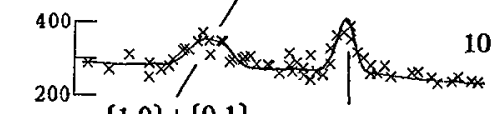

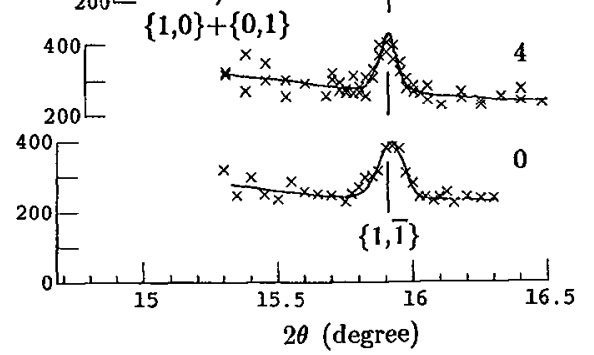

Fig. 4.

A. GID measurements integrated over $0 \leq \mathrm{q}_{\mathrm{z}} \leq 0.26 \AA^{-1}$ for a monolayer of PFA over pure water $(\mathrm{pH}=5.8)$ upon compression at point $c, d, e$, $f, g$ and $h$ on the $\pi-A$ isotherm (Fig. 3). The peak assignment to $h k$ reflections are also given.

B. GID patterns obtained for a PFA monolayer over pure water at point $a, b$, and $d$ on the $\pi-A$ isotherm for different given $\mathrm{q}_{\mathrm{z}}$-windows. Note that the measurements corresponding to different windows are displaced vertically for clarity. Leastsquare Lorentzian fits are shown for better viewing of the different peaks.
B

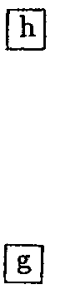

$\mathbf{f}$

e

d

c]
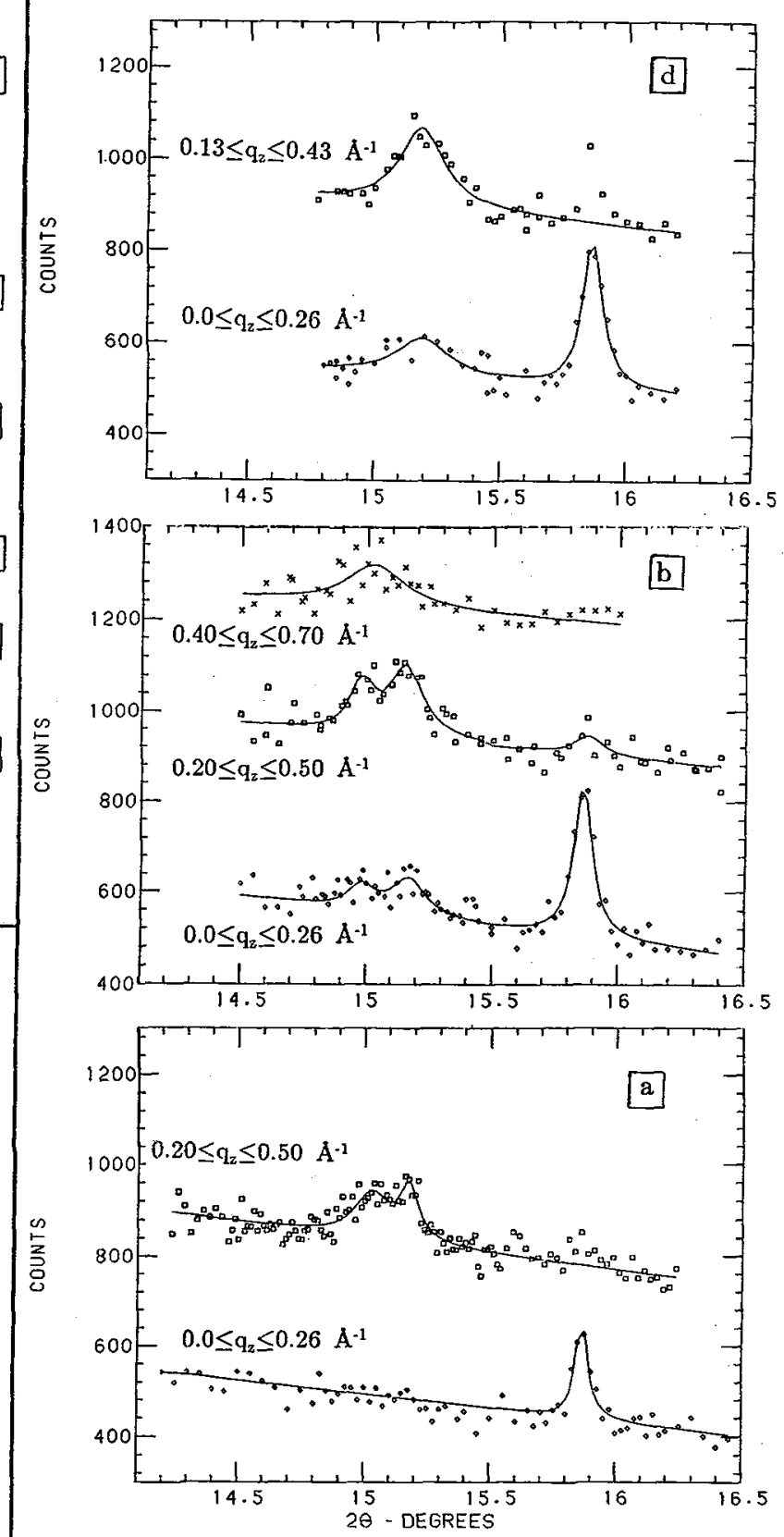

For the expanded monolayer with an average molecular area (points a, b and c Fig. 3 ) of 1.4 to 2.0 times the limiting area of $28.5 \AA^{2}$, i.e., for a surface coverage ranging from 50 to $70 \%$, three first order peaks were observed (Fig. $4 \mathrm{~B}$ ). Compression to $4 \mathrm{mN} / \mathrm{m}$ results in the two low angle peaks merging, leading to two observable Bragg signals (point d, Fig. 4B). Further compression to above about $20 \mathrm{mN} / \mathrm{m}$ shows merging of these two GID peaks leading to a single peak (point g, Fig. 4A). Upon decompression below about $25 \mathrm{mN} / \mathrm{m}$ the peak splits into two again [8], however no diffraction peak is observed for the expanded monolayer at $\pi=0 \mathrm{mN} / \mathrm{m}$, point $c$ (Fig. 3). This shows that decompression reduces the degree of crystallinity. 


\section{Characterization of the 2D crystalline structure of PFA}

Our starting point is the known crystalline structure of PFA at high surface pressures [8]. At these pressures the single intense peak indicates an hexagonal unit cell with the three lowest order reflections $\{1, \overline{1}\},\{1,0\}$ and $\{0,1\}$ coinciding and the spacing being $d_{0}=4.97 \AA$. This hexagonal packing is in keeping with the helical structure of the fluorocarbon chain. Stretched films of polytetrafluoroethylene [poly- $\left.\left(\mathrm{CF}_{2}\right)\right]$ have their fluorocarbon chains arranged in a hexagonal lattice with a $d$-spacing very similar to that of compressed PFA, and these chains adopt a helical conformation [10]. Also, crystal structures of small molecules with perfluorinated chains of length 6 or 7 have also shown helical conformation [11]. The stiffness of the helical fluorocarbon chain is probably responsible for increasing the ability of PFA to self assemble at zero surface pressure, since it reduces disorder in the crystalline packing of these chains.

At low measurable pressures in the range $1 \mathrm{mN} / \mathrm{m}$ to $20 \mathrm{mN} / \mathrm{m}$ the diffraction peak splits into two (Fig. 4), indicating a distortion of the hexagonal cell which is attributed to the molecules tilting rigidly from the vertical. Two models were proposed for the tilt direction: either (model I) towards, or (model II) in between nearest neighbours [8]. Tilts in other directions would result in splitting into a triplet rather than the observed doublet. The low angle peak in model $I$ is identified as the $\{1,0\}+\{0,1\}$ reflections and the other as the $\{1, \overline{1}\}$, while for model II the identification is reversed [8].

The distinct diffraction peaks observed in the GID results for $0 \mathrm{mN} / \mathrm{m}$ (point $a, b$ and $c$, Fig. 4) proves the existence of crystalline order even in this so called "liquid-expanded" phase. The observation of all three first order peaks implies that there is no longer an hexagonal cell (we find $a=5.84 \AA, b=5.92 \AA, \gamma=116.5^{\circ}$ ). The relative change in $|a+b|=6.19 / 5.74=$ 1.078 , corresponds to a tilt angle of $22^{\circ}$, on the assumption that the original contacts between chains are preserved at zero pressure. The high angle peak width (points a, $b$ and $c$, Fig. 4), equal to that of the high pressure peak (point h, Fig. 4), yields a crystalline coherence length greater that $1500 \AA$. This is a clear indication that the traditional monolayer phase assignment, based on macroscopic measurements, may in some systems be misleading.

\section{Specular reflectivity measurements}

A marked difference is also seen in the XR data collected for surface pressures above and below the transition pressure, shown in Fig. 5 . We analyze the reflectivity data by a 3-box model representing the vertical electron density variation across the monolayer. The three boxes correspond to the glycyl $\left(\mathrm{CH}\left(\mathrm{NH}_{3}+\mathrm{CO}_{2}^{-}\right)\right.$, ester $\left(\left(\mathrm{CH}_{2}\right)_{2}-\mathrm{OCO}-\mathrm{CH}_{2}\right)$, and fluorocarbon $\left(\mathrm{CF}_{3}\left(\mathrm{CF}_{2}\right)_{9}\right)$ parts containing 37,46 , and 249 electrons, respectively. Fitted parameters are the three box thicknesses, an overall smearing and the molecular area $[4 \mathrm{c}, 8,12]$. The resulting fits are shown by the solid lines in Fig. 5 . The fit for $28 \mathrm{mN} / \mathrm{m}$ yields box thicknesses of $1.7,4.4$ and $13.0 \AA$ giving a molecular length of $19.1 \pm 0.5 \AA$. For $12 \mathrm{mN} / \mathrm{m}$ fitted box thicknesses 1.3 , 4.2 and $12.3 \AA$ are obtained yielding a projected molecular length of $17.8 \pm 0.5 \AA$. This is a reduction by a factor $0.95=\cos \left(19^{\circ}\right.$ ) from the high pressure values (apart from an additional conformational change of the head-group). Simultaneously, the fitted molecular area increased from $29.6 \pm 1.0 \AA^{2}$ to $34.9 \pm 1.0 \AA^{2}$. These observations indicate that, with reduction of pressure, the molecules tilt approximately rigidly and the lattice strain is $\epsilon=(1 / \cos (t))-1$, $t$ being the tilt angle. Similar results were obtained with monolayers of arachidic acid [13]. The associated splitting of the GID peaks was shown $[8,13]$ to be $\Delta \mathrm{d}=3 / 4 \mathrm{~d}_{0} \cdot \epsilon$. For PFA using $\mathrm{t}=19^{\circ}$, this gives $\Delta \mathrm{d}=0.21 \pm 0.04 \AA$; in good agreement with the value of $0.18 \pm 0.05 \AA$ measured from the $10 \mathrm{mN} / \mathrm{m}$ GID data shown in Fig. $4 \mathrm{~A}$ where the two peak positions correspond to 4.98 and $5.16 \AA$.

Fig. 5. Reflectivity measurements for PFA on water. The solid lines are box model fits discussed in the text. $R / R_{F}$ is the measured reflectivity divided by the Fresnel reflectivity calculated for a perfect, sharp interface.

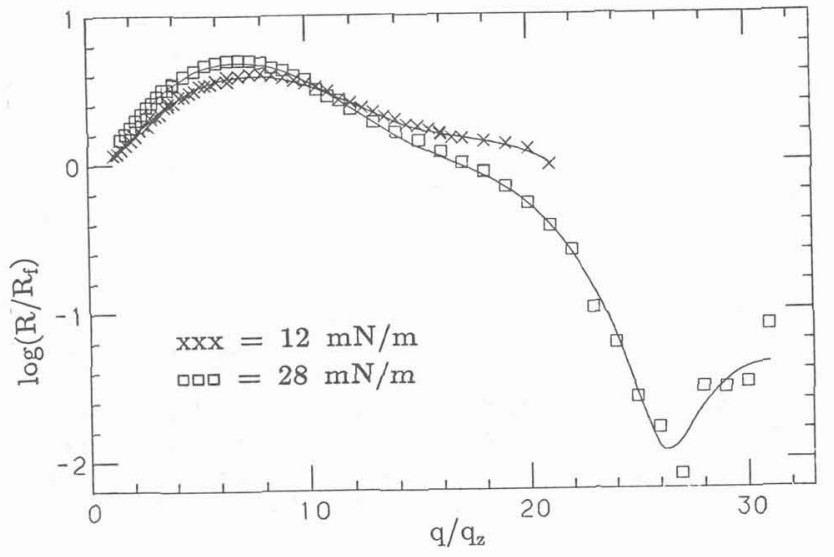




\section{Bragg rod scans}

Direct, unambiguous evidence for the tilt, its magnitude and direction is obtained from BR scans. The intensity distribution along $z$ is dominated by the vertical electron distribution in the crystalline part of the monolayer, in contrast with the XR where it is averaged over all of the monolayer. We measured Bragg rods for the self-assembled monolayer at point a at the three first order GID peaks (Fig. 4B); at point $c$ (Fig. 4A) at the high angle peak; at the high and low angle GID peaks at $10 \mathrm{mN} / \mathrm{m}$ (point e, Fig. 4A); and for the single peak position at $28 \mathrm{mN} / \mathrm{m}$ (point b. Fig. $4 \mathrm{~A}$ ), upon compression. These are given in Fig. 6 .

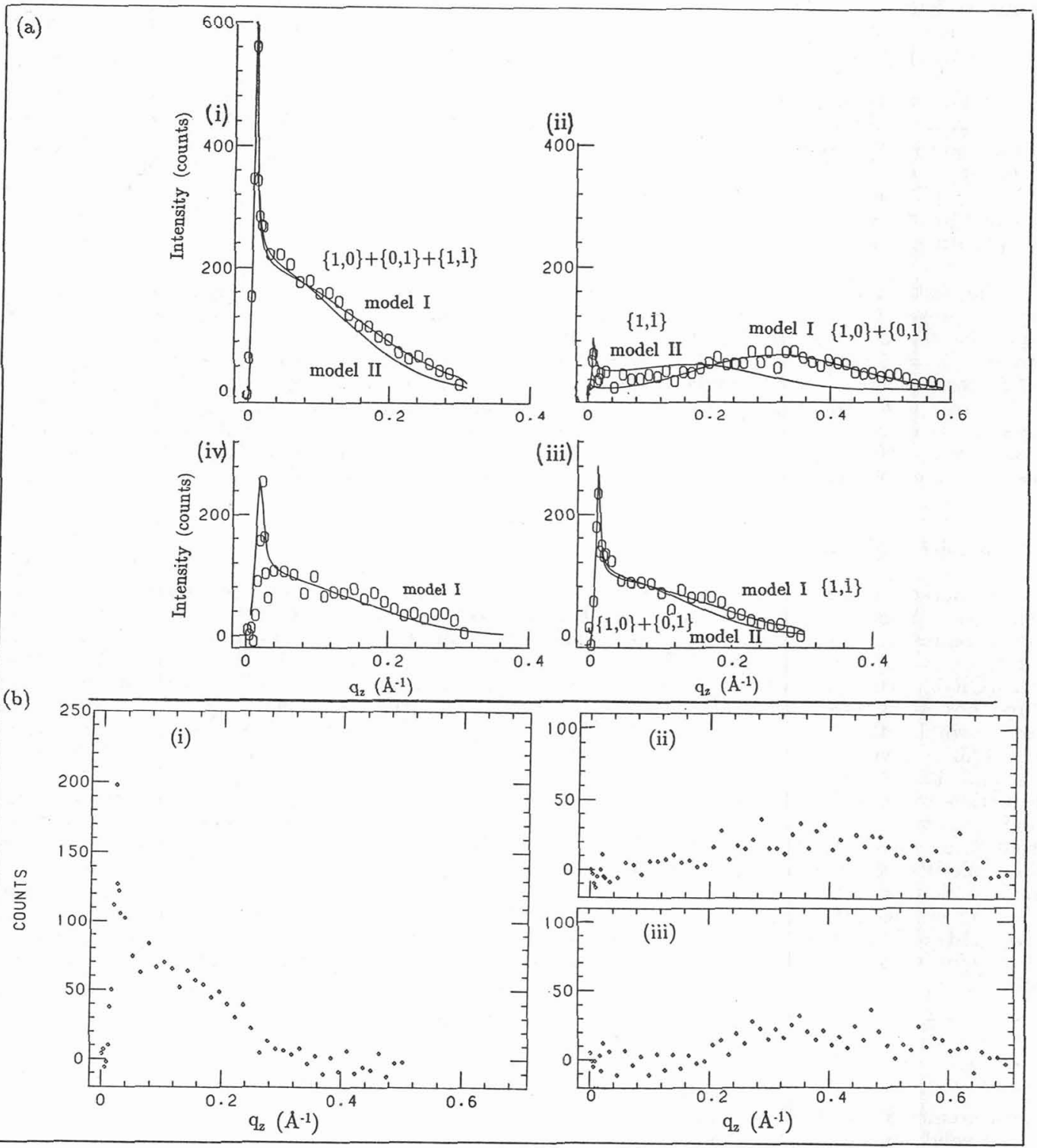

Fig. 6.

a. Bragg rod scans for PFA with calculated fits shown as solid lines; see text for details. Clockwise from upper left, measured at: (i) The single GID peak at $28 \mathrm{mN} / \mathrm{m}$, $2 \theta=15.96^{\circ}$. (ii) The low angle peak at $10 \mathrm{mN} / \mathrm{m}, 20=15.43^{\circ}$. (iii) The high angle peak at $10 \mathrm{mN} / \mathrm{m}, 2 \theta=15.92^{\circ}$. (iv) The high angle GID peak at $0 \mathrm{mN} / \mathrm{m}$ (point $\mathrm{c}$, Fig. $4 \mathrm{~A}$ ), $2 \theta=15.92^{\circ}$. Calculated $\{1, \overline{1}\}$ reflection (model I).

b. Bragg rod scans for PFA at $0 \mathrm{mN} / \mathrm{m}$ (point a, Fig. 4B) measured for: (i) $2 \theta^{\circ}=15.86^{\circ}$. (ii) $2 \theta=15.175^{\circ}$. (iii) $2 \theta=14.975^{\circ}$. Note the change in intensity-scale. 
Three methods for Bragg rod model calculations

The BR intensity distribution along $\mathrm{q}_{\mathrm{z}}, \mathrm{I}_{h k}\left(\mathrm{q}_{\mathrm{z}}\right)$ results from Fourier transforming the electron density of the crystalline part of the monolayer. Consider first a simple model treating the tilted molecule as a long cylindrical rod of finite length L. Upon Fourier transformation, we get $[14,13]$ :

$$
\mathrm{I}_{h k}\left(\mathrm{q}_{\mathrm{z}}\right) \approx \mathrm{I}_{0}[\sin \mathrm{W} / \mathrm{W}]^{2}
$$

where $W=0.5 L\left[q_{z} \cos (t)-q_{x} \sin (t)\right] . q_{z}$ is the vertical component of the scattering vector and $q_{x}$ is the component along the tilt direction. Explicitly, $\mathrm{q}_{\mathrm{x}}=\left|\mathrm{G}_{h k}\right| \cos \left(\psi_{h k}\right)$, where $\mathrm{G}_{h k}$ is the reciprocal lattice vector and $\psi_{h k}$ is the angle from $\overline{\mathrm{G}}_{h k}$ to the tilt direction $\hat{x}$.

Thus a bell shaped curve results, peaking at $\mathrm{W}=0$ with width $\Delta \mathrm{W}=2.78$, which, in turn, yields $\mathrm{L}=5.56 /\left(\Delta \mathrm{q}_{\mathrm{z}} \cos (\mathrm{t})\right)$ and $\tan (\mathrm{t})=\mathrm{q}_{\mathrm{z}}^{0} / \mathrm{q}_{\mathrm{x}}$ where $\mathrm{q}^{0}{ }_{\mathrm{z}}$ denotes the peak position of the curve and $\Delta \mathrm{q}_{\mathrm{z}}$ its width. The shapes of the measured curves in Fig. 6 clearly conform to this, disregarding the sharp peak at $\mathrm{q}_{2} \approx 0.01 \AA^{-1}$ (see discussion in the next paragraph). Note that for the curves peaking at $\mathrm{q}_{\mathrm{z}}^{0}=0$ only half of the rod is observable above horizon (Fig 6a.i,iii,iv and Fig 6b.i). Measuring $\Delta \mathrm{q}_{\mathrm{z}}$ in Fig. $6 \mathrm{a}$, we obtain $\mathrm{L} \approx 20 \AA$. The BR bell shape is fully observed for the $\{1,0\}+\{0,1\}$ reflections at $10 \mathrm{mN} / \mathrm{m}$ (Fig. 6a.ii). A crude ruler-measurement in this case yields $\mathrm{L}=20 \AA, \mathrm{q}^{0}{ }_{\mathrm{z}}=0.33 \AA^{-1}$ and $\mathrm{t}=18^{\circ}$, all in excellent agreement with the GID and XR results.

More detailed analysis can be done as follows [2]. The molecule is modeled by a cylinder of length $L$ made up of $n=3$ sections each of length $l_{n}$, constant electron density $a_{n}$ and centered on $z=c_{n}$. Since the sample is a 2D powder [8] the observed BR intensity, $\mathrm{I}^{\circ b s}\left(\mathrm{q}_{\mathrm{z}}\right)$, contains contributions from several $(h k$ ) reflections (as indicated in Fig. 6a):

$$
\mathrm{I}^{\mathrm{obs}}\left(\mathrm{q}_{\mathrm{z}}\right)=\mathrm{I}_{0} \sum_{\bar{h} k}\left\{\mathrm{I}_{h k}\left(\mathrm{q}_{\mathrm{z}}\right)+\mathrm{I}_{\bar{h} \bar{k}}\left(\mathrm{q}_{\mathrm{z}}\right)\right\}
$$

Here, $\quad \mathrm{I}_{h k}\left(\mathrm{q}_{\mathrm{z}}\right)=\left|\mathrm{V}(\mathrm{x}) \cdot \mathrm{F}\left(\mathrm{G}_{h k} ; \mathrm{q}_{\mathrm{z}}\right)\right|^{2} \exp \left[-\mathrm{q}_{\mathrm{z}}^{2} \sigma^{2}\right]$. In the cylinder model, the structure factor $\mathrm{F}\left(\mathrm{G}_{h k} ; \mathrm{q}_{z}\right)=\sum \mathrm{a}_{\mathbf{n}} \mathrm{l}_{\mathrm{n}} \mathrm{S}_{\mathrm{n}}(\mathrm{u})$ where $\mathrm{u}=\mathrm{q}_{\mathrm{z}} \cos (\mathrm{t})-\mathrm{q}_{\mathrm{x}} \sin (\mathrm{t}), \mathrm{S}_{\mathrm{n}}(\mathrm{u})=\exp \left(-\mathrm{i} \cdot \mathrm{c}_{\mathrm{n}} \cdot \mathrm{u}\right) \sin \left(0.5 \cdot \mathrm{l}_{\mathrm{n}} \mathrm{u}\right) /\left(0.5 \cdot \mathrm{l}_{\mathrm{n}} \mathrm{u}\right)$. The Vineyard function $V(x)$ describes the interference between the diffracted and diffracted and subsequently reflected waves $[15,16]$; it is seen as a sharp peak at $\mathrm{q}_{z} \approx 0.01 \AA^{-1}$. Explicitly, $\mathrm{V}(\mathrm{x})=2 \mathrm{x}$ for $\mathrm{x}<1$ and $=2 \mathrm{x} /\left[\mathrm{x}+\left(\mathrm{x}^{2}-1\right)^{1 / 2}\right]$ for $\mathrm{x}>1$ where $\mathrm{x}=2 \mathrm{q}_{\mathrm{z}} / \mathrm{q}_{\mathrm{c}}$ and $\mathrm{q}_{\mathrm{c}}=(4 \pi / \lambda)$ sin $\alpha_{\mathrm{c}}=$ $0.021764 \AA^{-1}$. The Debye-Waller factor $\exp \left(-\mathrm{q}_{\mathrm{z}}{ }^{2} \sigma^{2}\right)$ accourts for the surface roughness.

Using the box lengths $l_{n}$ and electron densities $a_{n}$ obtained from the XR fits at high pressure, we refine $I_{0}$ and $t$ by fits to the $B R$ data for each of the two models. Finite resolution effects were also included. The results of the fits are shown in Fig. 6a as solid lines through the data. Both models I and II fit the high pressure BR (Fig. 6a.i) well and a tilt $t=5^{\circ}$ is obtained. The resultant splitting in the GID peak from such a small tilt cannot be resolved. For model I the BR's at $10 \mathrm{mN} / \mathrm{m}$ (Fig. 6a.ii,iii) yield $\mathrm{t}=19^{\circ}$ in excellent agreement with the GID and XR results. Model II, on the other hand, for a non-zero tilt $t$, implies a peak position $q_{i}^{0}>0$ for the $\{1,1\} \quad B R$ (see Fig. 6a.ii) and concomitantly a peak position $\mathrm{q}_{\mathrm{z}}^{0}\left(\mathrm{~d}_{11} \cos \left(\psi_{10}\right)\right) /\left(\mathrm{d}_{10} \cos \left(\psi_{1 i}\right)\right) \approx \mathrm{q}_{2}^{0} / 2$ for the other BR $(\{0,1\}+\{1,0\}$, see Fig. 6a.iii). This is evidently inconsistent with the data. Quantitatively, fitting the data of Fig. 6a.iii gives $t=9{ }^{\circ}$, which in turn results in a very poor fit for the BR in Fig. 6a.ii. Furthermore, based on the number of contributing reflections the approximate ratio of intensities $\mathbf{I}_{0}{ }^{\mathbf{a}}: \mathbf{I}_{0}{ }^{\mathrm{b}}: \mathrm{I}_{0}{ }^{\mathrm{c}}$ expected is $3: 2: 1$ for model I and 3:1:2 for model II. The fitting gave 4.5:2:1 for model I and 4:1:1 for model II. These results strongly favour model I over model II as well. Correcting the observed ratio $I_{0}{ }^{a}: I_{0}{ }^{c}$ for the increase of molecular area of the tilted phase (as determined from the $2 \theta$ peak position listed in the figure caption of Fig. 6a) yields 4.1:1 instead of 4.5:1. This is still in excess of the multiplicity ratio of 3:1. The explanation may be that at low pressures the monolayer coverage of the water surface is less than $86 \%$ [8]. Together with an experimental uncertainty of less than $20 \%$ the apparent discrepancy between model and experimental is reconciled. A similar effect with the same magnitude was also noticed in earlier GID integrated intensity results [8]. We therefore conclude that the GID, XR and, in particular, the BR measurements clearly show model I to be correct and rule out model II.

We have also analyzed the BR data by calculating the molecular structure factor from an atomic coordinate model of the molecule: Each atom $(j)$, with form factor $f_{j}$, is at position $\overrightarrow{\mathrm{r}}_{\mathrm{j}}+\hat{z}_{\overrightarrow{\mathrm{b}}} \cdot z_{\mathrm{j}}$, where $\overrightarrow{\mathrm{r}}_{\mathrm{j}}=x_{\mathrm{j}} \overrightarrow{\mathrm{a}}+y_{\mathrm{j}} \overrightarrow{\mathrm{b}}$. $\overrightarrow{\mathrm{a}}$ and $\overrightarrow{\mathrm{b}}$ are unit cell axes; $\hat{z}$ is a unit vector normal to $\overrightarrow{\mathrm{a}}$ and $\vec{b}$. Thus, the molecular structure factor is:

$$
\mathrm{F}\left(\overrightarrow{\mathrm{G}}_{h k ;} ; \mathrm{q}_{\mathrm{z}}\right)=\operatorname{Jf}_{\mathrm{j}} \cdot \exp \left[\mathbf{i}\left(\overrightarrow{\mathrm{G}}_{h k} \cdot \overrightarrow{\mathrm{r}}_{\mathrm{j}}+\mathrm{q}_{\mathrm{z}} \cdot z_{\mathrm{j}}\right)\right]
$$


With this modification, the calculations were as described above. The high pressure BR (Fig. 6a.i) was fit best by a molecular model where the overall molecular length was $19 \pm 0.5 \AA$, and the molecule stands straight vertically. The best fit for the $B R$ data at $10 \mathrm{mN} / \mathrm{m}$ (Fig. 6a.ii,iii) was for model I with $t=20^{\circ}$. Finally, for the self-aggregated monolayer (Fig. 6a.iv), a fit was made for the higher angle first order peak. The fit in the figure uses the molecular model and is calculated as described above. It fits the data with the $\{1, \hat{1}\}$ reflection and a tilt of $\grave{t}=25 \pm 5^{\circ}$ (model I). The ratio between the factors which scale between the data and calculated BR intensities at 28 and $0 \mathrm{mN} / \mathrm{m}$ (point c, Fig. 6a.iv) is 0.75 , which is in good agreement with the $70 \%$ coverage of the uncompressed monolayer at this point. This also implies that practically all of the molecules are contained in the self-aggregated crystalline clusters at point $c$ (Fig. 3). This in turn would imply that the onset of surface pressure at $\approx 32 \AA^{2}$ in Fig. 3 coincides with these crystalline clusters coming into contact.

Finally, GID measurements were performed 3$]$ for a range of subphase $\mathrm{pH}$ values where $\mathrm{KOH}$ and $\mathrm{HCl}$ was used to vary the $\mathrm{pH}$. For $\mathrm{pH}=11.5$ ( $\mathrm{KOH}$ in solution) and $\pi=0 \mathrm{mN} / \mathrm{m}$ only one fully developed peak was found, of intensity comparable to that measured over pure water at high pressure. Compression to $25 \mathrm{mN} / \mathrm{m}$ leaves the intensity and $\mathrm{BR}$ shape unchanged, showing the peak to result from overlapping $\{1, \overline{1}\}+\{1,0\}+\{0,1\}$ reflections. Moreover, upon decompression to $0 \mathrm{mN} / \mathrm{m}$, crystallinity was maintained, with no splitting of the single peak, unlike over water. Thus, the binding of the $\mathrm{K}+$ cation at the head group level seems to stabilize a hexagonal cell with upright molecules even at practically zero surface pressure.

\section{4 - CONCLUSIONS}

The results presented above show that by combining GID, XR and BR measurements it is possible to characterize in some detail the in-plane and vertical structure of a Langmuir monolayer at the molecular level in a system undergoing surface pressure driven phase transitions. We have further observed self-assembly of crystalline clusters for expanded monolayers, where no more than $50 \%$ of the surface is covered by the monolayer material. Furthermore, the ratio of the calculated $B R$ intensity scale factors for $28 \mathrm{mN} / \mathrm{m}$ and $0 \mathrm{mN} / \mathrm{m}$ indicate that practically all the monolayer material is contained in the crystalline clusters. We note that upon decompression to point $\mathrm{c}$ in Fig. 3, PFA does not give any GID signal over water, indicating hysteresis in the surface pressure-driven phase transitions. We may conclude that floating amphiphiles with rigid chains and strongly interlinked head-groups self-assemble into crystalline clusters. These results provide incentive for the design of rigid surfactant molecules with clustering properties at the interface which may be monitored by $\mathrm{X}$-ray diffraction and Bragg rod measurements. The results indicate that with the availability of such detailed analyses some of our earlier concepts about the structure of monolayers, derived from macroscopic measurements, will have to be revised.

Beamtime at HASYLAB, Hamburg is gratefully acknowledged, as is the support of the U.S./Israel Binational Science Foundation, The Petroleum Fund of the American Chemical Society, The Fund for Basic Research of the Israel Academy of Sciences and Humanities, The Minerva Foundation and the Danish Foundation for Natural Sciences.

\section{REFERENCES}

1. (a) Grayer Wolf S., Leiserowitz L., Lahav M., Deutsch M., Kjaer K., and Als-Nielsen J., Nature, 328, 63-66 (1987). (b) Kjaer K., Als-Nielsen J., Helm C.A., Laxhuber L.A. and Möhwald H., Phys. Rev. Lett., 58, 2224 (1987). (c) Dutta P., Peng J.B., Lin B., Ketterson J.B., Prakash M., Georgopolus P. and Ehrlich S., Phys. Rev. Lett., 58, 2228 (1987). (d) Helm C.A., Möhwald H., Kjaer K. and Als-Nielsen J., Biophys. J., 52, 381-390 (1987).

2. Grayer Wolf S., Jacquemain D., Leveiller F., Lahav M., Leiserowitz L., Deutsch M., Kjaer K., and Als-Nielsen J., submitted to Phys. Rev. Lett.

3. Jacquemain D., Grayer Wolf S., Leveiller F., Lahav M., Leiserowitz L., Deutsch M., Kjaer K., and Als-Nielsen J., submitted to J. Am. Chem. Soc.

4. (a) Als-Nielsen J., Christiensen F. and Pershan P.S., Phys. Rev. Lett., 48, 1107 (1982). (b) Braslau A., Deutsch M., Pershan P.S.; Weiss A.H., Als-Nielsen J., and Bohr J., Phys. Rev. Lett., 54, 114 (1985). (c) Helm C.A., Möhwald H., Kjaer K. and Als-Nielsen J., Europhys. Lett., 4, 697-703 (1987). (d) Richardson R.M. and Roser S.J., Liquid Crystals, 2, 797-814 (1987). 
5. (a) Landau E.M., Levanon M., Leiserowitz L., Lahav M. and Sagiv J., Nature, 318, 353-356 (1985). (b) Landau E.M., Grayer Wolf S., Levanon M., Leiserowitz L.,

Lahav M. and Sagiv J., J. Am. Chem. Soc., 111, 1436-1445 (1989). (c) Landau E.M., Popovitz-Biro R., Levanon M., Leiserowitz M. and Lahav M., Mol. Cryst. Liq. Cryst., 134, 323 (1986).

6. Almlöf J., Kvick $\AA$. and Thomas J.O., J. Chem. Phys., 59, 3901-3906 (1973).

7. Grayer Wolf S., Landau E.M., Lahav M., Leiserowitz L., Deutsch M., Kjaer K. and Als-Nielsen J., Thin Solid Films, 159, 29-41 (1988).

8. Grayer Wolf S., Deutsch M., Landau E.M., Lahav M., Leiserowitz L., Kjaer K. and Als-Nielsen J., Science, 242, 1286-1290 (1988).

9. Gaines Jr. G.L., Insoluble Monolayers at Liquid-Gas Interfaces, Wiley, New York (1966).

10. Bunn C.W. and Howells E.R., Nature, 174, 549 (1954).

11. X-ray diffraction studies performed in our laboratory.

12. Parratt, L.G., 'Phys Rev., 95, 359 (1954).

13. Kjaer, K., Als-Nielsen J., Helm C.A., Tipman-Krayer P., Möhwald H., J. Phys. Chem., 93, 3200-3206 (1989).

14. Guinier, A., X-ray Diffraction, Freeman, San Francisco (1968) pp. 121-125.

15. Vineyard G., Phys. Rev. B, 26, 4146 (1982).

16. Feidenhans'l, R., Surf. Sci. Rep., Vol. 10, no. 3 (1989) pp.105. 